\title{
Effects of the Circadian Rhythm Gene Period 1 (Per1) on Psychosocial Stress-Induced Alcohol Drinking
}

\author{
Li Dong, Ph.D. \\ Ainhoa Bilbao, Ph.D. \\ Manfred Laucht, Ph.D. \\ Richard Henriksson, Ph.D. \\ Tatjana Yakovleva, Ph.D. \\ Monika Ridinger, M.D. \\ Sylvane Desrivieres, Ph.D. \\ Toni-Kim Clarke, Ph.D. \\ Anbarasu Lourdusamy, Ph.D. \\ Michael N. Smolka, M.D. \\ Sven Cichon, Ph.D. \\ Dorothea Blomeyer, Ph.D. \\ Jens Treutlein, Ph.D. \\ Stephanie Perreau-Lenz, Ph.D. \\ Stephanie Witt, Ph.D. \\ Fernando Leonardi-Essmann, \\ M.Sc.
}

Norbert Wodarz, M.D.

Peter Zill, M.D.

Michael Soyka, M.D.

Urs Albrecht, Ph.D.

Marcella Rietschel, M.D.

Mark Lathrop, Ph.D.

Georgy Bakalkin, Ph.D.

Rainer Spanagel, Ph.D.

Gunter Schumann, M.D.

Objective: Circadian and stress-response systems mediate environmental changes that affect alcohol drinking. Psychosocial stress is an environmental risk factor for alcohol abuse. Circadian rhythm gene period 1 (Per 1 ) is targeted by stress hormones and is transcriptionally activated in corticotropin releasing factor-expressing cells. The authors hypothesized that Per1 is involved in integrating stress response and circadian rhythmicity and explored its relevance to alcohol drinking.

Method: In mice, the effects of stress on ethanol intake in mPer1-mutant and wild-type mice were assessed. In humans, single nucleotide polymorphisms (SNPs) in $h P e r 1$ were tested for association with alcohol drinking behavior in 273 adolescents and an adult case-control sample of 1,006 alcohol-dependent patients and 1,178 comparison subjects. In vitro experiments were conducted to measure genotype-specific expression and transcription factor binding to hPer1.

Results: The mPer1-mutant mice showed enhanced alcohol consumption in response to social defeat stress relative to their wild-type littermates. An association with the frequency of heavy drinking in adolescents with the hPer 1 promoter SNP rs3027172 and with psychosocial adversity was found. There was significant interaction between the rs 3027172 genotype and psychosocial adversity on this drinking measure. In a confirmatory analysis, association of hPer1 rs3027172 with alcohol dependence was shown. Cortisol-induced transcriptional activation of hPer1 was reduced in human Blymphoblastoid cells carrying the risk genotype of rs3027172. Binding affinity of the transcription factor Snail1 to the risk allele of the $h$ Per1 SNP rs3027172 was also reduced.

Conclusions: The findings indicate that the $h P e r 1$ gene regulates alcohol drinking behavior during stressful conditions and provide evidence for underlying neurobiological mechanisms.

\begin{abstract}
A
Icohol use disorders are the result of cumulative responses to alcohol exposure, the genetic makeup of an individual, and environmental perturbations over time (1). Understanding how environmental influences moderate genetic risk (gene-by-environment interactions) is crucial for the elucidation of mechanisms underlying alcohol use disorders.

Stress responses and circadian rhythmicity are adaptations to environmental influences. Whereas stress responses are adaptations to unpredictable aspects of the environment, circadian rhythmicity is an adaptation to its predictable aspects, such as light-dark cycles $(2,3)$. The hypothalamic-pituitary-adrenal axis and the extrahypo-
\end{abstract}

thalamic brain stress system mediate behavioral and neuroendocrine reactions to stress in animals and humans (2, 4). Both systems are under circadian control and thus provide an optimal adaptive response to environmental influences $(2,5,6)$. One important environmental risk factor for the development of alcohol use disorders is psychosocial stress. Exposure to early adverse life stress increases the risk of alcohol dependence in later life, and psychosocial stress in individuals abstinent from alcohol consumption increases alcohol craving and the propensity for relapse (7-9). In addition, stress-induced alcohol consumption can lead to disturbances in circadian rhythmicity, which might further exacerbate the use of alcohol (10). 
Although the interaction of stress response and circadian systems and their relevance to alcohol use have been documented at the behavioral and neuroendocrinological levels, the underlying integrative neurobiological mechanisms are not well established.

The molecular basis of circadian rhythmicity (circadian clock) involves a primary loop, with period 1, 2, and 3 (Per1, Per2, and Per3) and cryptochrome 1 and 2 (CRY1 and CRY2) proteins as transcriptional repressors and clock (homologue NPAS2 [neuronal period aryl hydrocarbon receptor nuclear translocator single-minded domain protein 2]) and BMAL1 (brain and muscle aryl hydrocarbon receptor nuclear translocator-like protein 1) proteins as transcriptional activators. This feedback cycle provides near-24hour timing and drives the rhythmic expression of several clock-controlled and clock-modulated genes, which in turn mediate circadian rhythms in behavior and physiology. The circadian clock synchronizes and dictates the relative phasing of diverse internal physiological processes and molecular pathways. Clock genes also participate in reciprocal regulatory feedback, thereby rendering the circadian clock responsive to the internal environment of the body (11).

There is increasing evidence that the circadian clock gene Perl is a target gene for glucocorticoids in mice (12) and humans (13) as well as stress-induced transcriptional activation in corticotropin releasing factor-expressing cells (14). We hypothesized that Perl might be involved in the integration of stress response and circadian rhythmicity and aimed to explore this gene's relevance to alcohol drinking behavior.

\section{Method}

\section{Behavioral Animal Experiments}

We examined mice with a mutation of the clock gene $\left(\operatorname{Per}^{\mathrm{Brdml}}\right)$. The suppression of this gene results in a behavioral alteration of clock phase. Mice deficient for $m P e r 1$ have no circadian rhythms in locomotor activity, nor do they have clock or clock-controlled gene expression (15) (see the data supplement accompanying the online version of this article). The effect of three different stressors on ethanol intake was tested. Once alcohol intake was stable, the mice underwent 3 consecutive days of one stressor, and drinking data were compared with that from the last 3 days of the baseline. The stressors consisted of 6 minutes of swim stress (basin height: $10 \mathrm{~cm}, 21^{\circ} \mathrm{C}$ ), 5 minutes of unexpected foot shock (0.150 mA; duration: 1-3 seconds; time interval: 1-15 seconds), and a social defeat test in which intruder Per1 mice and wild-type mice were allowed to interact with an aggressive CD-1 mouse for 15 minutes, during which time the Per1 and wild-type mice were attacked (see the data supplement).

\section{Adolescent Sample}

Adolescents were recruited via the Mannheim Study of Children at Risk, an epidemiological cohort study examining the outcome of early risk factors from infancy into adulthood $(16,17)$. The present investigation encompassed 273 adolescents (boys: $\mathrm{N}=130$, girls $=\mathrm{N}=143$ ) who participated in the 18-year assessment and for whom genetic data were available (see the data supplement). Adolescents participated in a telephone interview regarding their current drinking behavior. The total amount of alcohol intake during the last 6 months was measured using the Lifetime
Drinking History questionnaire. Two drinking variables were derived indicating the average amount of alcohol consumed per drinking day and the frequency of heavy drinking per month, defined as consumption of more than five (four for female adolescents) standard drinks (each with 8-12 g of alcohol) in a row. Data on psychosocial adversity according to an "enriched" family adversity index, as proposed by Rutter and Quinton (18), were derived from a standardized parent interview conducted at the 3-month follow up evaluation, which assessed characteristics of parents, partnership, and family environment during a period of 1 year prior to birth (mean score $=1.93[\mathrm{SD}=2.06]$; range $=0-7$ ) (see Table 1 in the data supplement).

\section{Adult Case-Control Sample}

A total of 1,006 adult patients with alcohol dependence were recruited from the Department of Psychiatry at the University of Regensburg (Regensburg, Germany). Patients were admitted consecutively for inpatient treatment and met criteria for alcohol dependence according to DSM-IV. A total of 1,178 individuals were recruited via the University of Bonn (Bonn, Germany) from 2001 to 2003, as part of the German National Genome Research Project, to serve as a comparison sample for genetic studies of several neuropsychiatric phenotypes. For further details on the adult case-control sample, see Table 1 in the data supplement. Informed consent was obtained from all human subjects. All studies were approved by the relevant ethics committees

\section{Mutation Screening and Identification of Single Nucleotide Polymorphisms (SNPs)}

SNPs were identified by sequencing 32 Caucasian DNA samples. Sixteen DNA pools consisting of an equimolar mixture of two DNA samples were prepared and used as polymerase chain reaction (PCR) templates. SNPs were genotyped using the TaqMan system. Probes and primers were created using Assay-onDemand (Applied Biosystems, Foster City, Calif.).

\section{Statistical and Bioinformatic Analysis of Human Data}

Data for minor allele frequencies for SNP makers, Hardy-Weinberg equilibrium tests, and the Cochran-Armitage trend test for single SNP association were calculated using PLINK software (http://pngu.mgh.harvard.edu/ purcell/plink/gplink.shtml). To examine gene-by-environment effects on adolescent drinking, linear-regression analyses were performed with sex as a covariate. Models were fitted for the main effects of the hPer1 rs3027172 genotype and psychosocial adversity ratings, with subsequent addition of the interaction term. Significant interactions were further investigated using simple main-effects analyses or simple contrasts. Genotype groups did not differ with regard to sex, age, IQ, and psychosocial adversity (see Table 1 in the data supplement).

\section{Cellular Experiments}

Epstein-Barr virus-transformed human B-lymphoblastoid cell lines were established from patients' blood lymphocytes, genotype-specific for rs3027172 in the $h$ Perl gene. There were seven cell lines carrying the TT allele and six cell lines with the CC allele. For baseline hPerl expression analysis, cells were synchronized with $50 \%$ horse serum. For detailed information on standard methods for quantitative real-time PCR, cortisol stimulation, electrophoretic mobility shift assay, and western blot, see the data supplement.

\section{Results}

\section{Enhanced Stress-Induced Alcohol Consumption in Per1 ${ }^{\text {Brdm1-Mutant Mice }}$}

We investigated stress-induced alcohol consumption in $\mathrm{Per}^{\mathrm{Brdml} 1}$-mutant and wild-type mice. As in our previ- 
ous report (19), basal alcohol intake in $\operatorname{Perl}^{B r d m 1}$-mutant mice did not differ from that of wild-type mice, except for a disruption of circadian intake patterns (see Figure 1 in the data supplement). When exposed for 3 consecutive days to social defeat stress, which models psychosocial adversity (20), mice with both genotypes showed significantly enhanced alcohol intake following social defeat stress. However, stress-induced alcohol consumption was significantly more pronounced in $\operatorname{Perl}^{\text {Brdml }}$-mutant mice (repeated-measures analysis of variance: stress-bygenotype interaction: $\mathrm{F}=6.8, \mathrm{df}=3,42, \mathrm{p}=0.0008$ ) (Figure 1). This genotype difference became further evident with repeated swim stress (stress-by-genotype interaction: $\mathrm{F}=4.1, \mathrm{df}=3,140, \mathrm{p}=0.004$ ) (see Figure 1 in the data supplement) and foot shock stress (stress-by-genotype interaction: $\mathrm{F}=10.1, \mathrm{df}=3,117, \mathrm{p}=0.000006)$, demonstrating that different stressors led to enhanced alcohol consumption in the Per $1^{\text {Brdm1 }}$-mutant mice. However, social defeat stress produced the most pronounced effect. Since blood corticosterone levels following stress were similar in both wild-type and Per $1^{\text {Brdml }}$-mutant mice (see Figure 1 in the data supplement), we ruled out a corticosterone-induced increase in alcohol intake (16). Thus, we demonstrated a stress-induced gene-by-environment interaction resulting in increased alcohol consumption, which was not dependent on an altered corticosterone response in the Per1 ${ }^{\text {Brdm1 }}$-mutant mice.

\section{hPer1 Haplotype Association With Frequency of Heavy Drinking in Adolescents}

To examine the possible role of $h P e r l$ in stress-induced gene-by-environment interactions mediating adolescent drinking behavior, we first sequenced regulatory domains, exons, and exon/intron boundaries of this gene in 32 participants from the Centre d'Etude du Polymorphisme Humain reference sample (http://www.cephb.fr/en/ cephdb/). We identified 18 genetic variations (two SNPs in the 5'UTR-region; four synonymous SNPs in exons; and 12 variations in introns). Nine of the genetic variations detected were not present in the Single Nucleotide Polymorphism Database (see Table 2 in the data supplement). We selected three haplotype tagging SNPs (rs3027172, rs2304911, and rs2735611) to identify the main haplotypes with a frequency $>10 \%$ (Figure 2). We genotyped these haplotype tagging SNPs in a population-based sample of 273 adolescents from the Mannheim Study of Children at Risk $(16,17)$ (see Table 1 in the data supplement) and analyzed haplotypes for association with the frequency of heavy drinking per month, a measure of risky drinking behavior. An omnibus test showed significant association with the frequency of heavy drinking $(\mathrm{p}<0.02$, Bonferroni corrected; log likelihood ratio=9.259), and haplotypespecific tests revealed significant association of the TTC haplotype with this phenotype (beta $=0.495, \mathrm{p}=0.003$ [after 10,000 permutations]) (Table 1). The association observed using the omnibus test did not remain significant when
FIGURE 1. Effects of Social Defeat Stress on Alcohol Drinking Behavior in Wild-Type and Per1 ${ }^{\text {Brdm1 }}$-Mutant Mice ${ }^{\text {a }}$

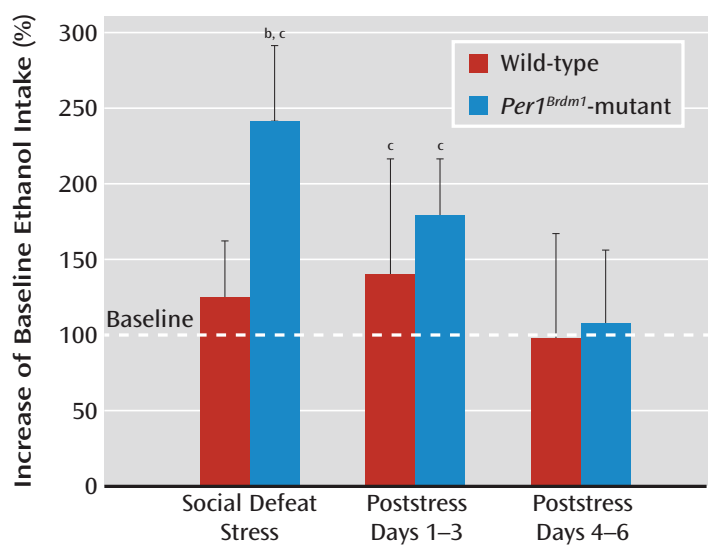

${ }^{a}$ Drinking data (3-day periods) are depicted as the percentage of increase with respect to the last 3 days of baseline drinking. Exposure to social defeat stress resulted in a significant increase in alcohol intake among both genotypes $(p<0.05)$. The Per1 ${ }^{\text {Brdm }}$-mutant mice showed augmented alcohol intake relative to wild-type mice (Newman-Keuls test, $p<0.01)$. Both genotypes recovered to baseline drinking levels after 3 days following stress application (poststress days 4-6).

${ }^{\mathrm{b}}$ Significant difference between genotypes was observed.

Significant stress-induced alcohol intake relative to baseline drinking was observed.

we dropped SNP rs3027172, suggesting that haplotypic association is driven by this SNP. Therefore, we selected rs3027172 for subsequent analyses.

\section{Effects of Psychosocial Stress on Heavy Drinking Frequency Moderated by hPer1 SNP rs3027172}

We then assessed whether the effect of psychosocial adversity on risky alcohol drinking in the Mannheim Study of Children at Risk sample was moderated by the rs3027172 genotype. In addition to the frequency of heavy drinking $(\mathrm{p}=0.008$, Bonferroni corrected), linear regression revealed a main effect of the rs3027172 genotype on the average amount of alcohol consumed $(\mathrm{p}<0.02$, Bonferroni corrected). Psychosocial adversity had a significant effect on these drinking measures, and there was a significant interaction effect between the rs3027172 genotype and psychosocial adversity on the frequency of heavy, excessive drinking but not regular drinking (Table 2). For the purpose of illustration, genotypes in Figure 2 are classified according to the presence of the minor $\mathrm{C}$ allele (risk allele), and psychosocial adversity was determined using a tripartite split in the psychosocial adversity ratings (low: $0-1$, moderate: $2-3$, and high: $\geq 4$ ). This interaction indicates that carriers of the $\mathrm{C}$ allele who had been exposed to severe adversity displayed a higher frequency of heavy drinking than homozygous carriers of the T allele. In contrast, no association between genotype and frequency of heavy drinking was detected among individuals who had been exposed to low or moderate adversity. 
FIGURE 2. Human Period 1 (hPer1) Haplotype Single Nucleotide Polymorphisms (SNPs) Associated With Heavy Drinking in Adolescents $(\mathrm{N}=273)^{\mathrm{a}}$

A
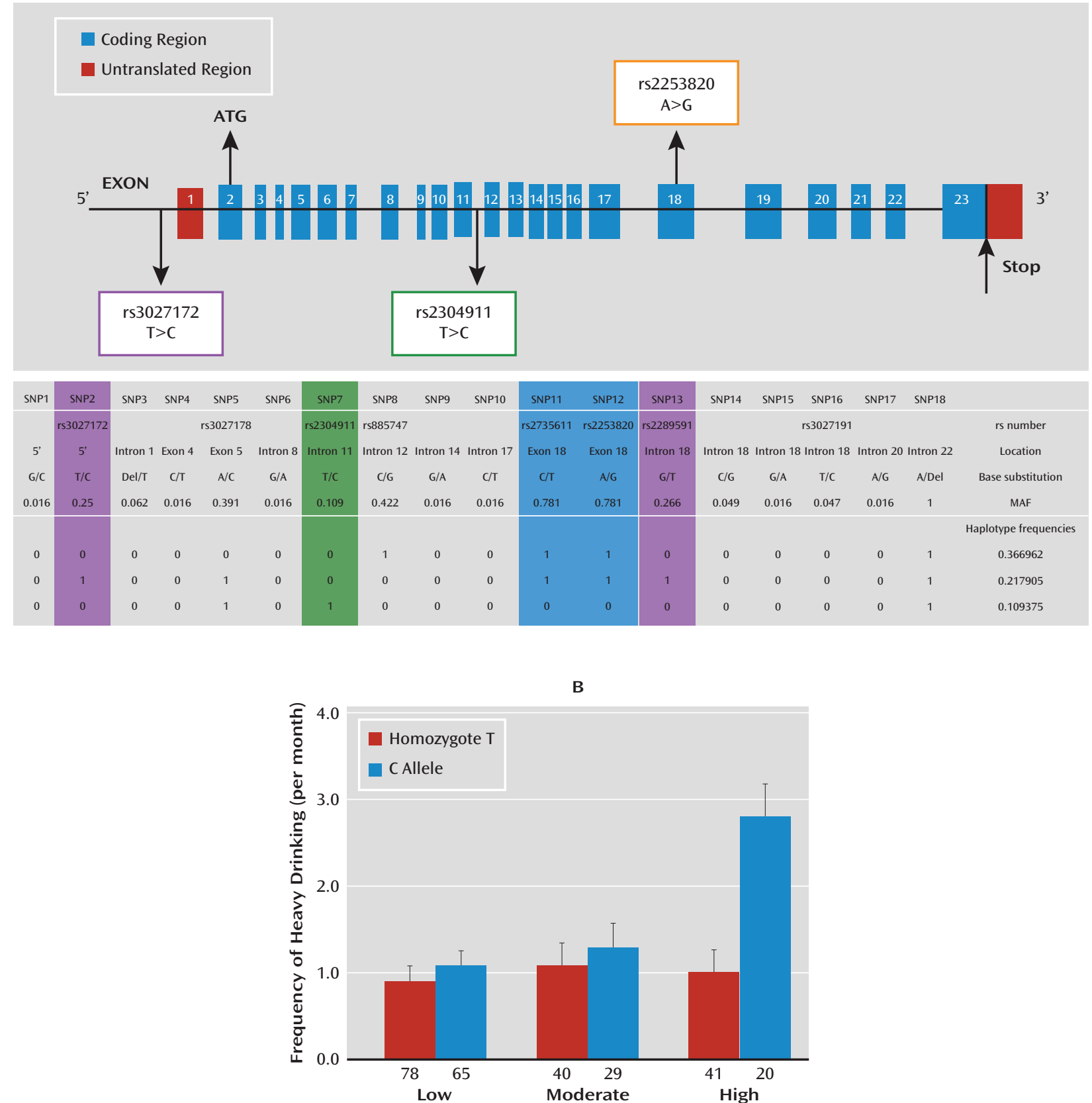

Psychosocial Adversity

a The top image (A) depicts hPer1 haplotype SNPs. A map of the Per1 gene shows the exons (boxes) and introns (solid lines) and the position of the haplotype SNPs discriminating haplotypes with a frequency $>10 \%$ (image size is not to scale). The bottom image (B) depicts the frequency of current monthly heavy drinking, adjusted for sex, in adolescents grouped by the $h P e r 1$ rs3027172 genotype and exposure to psychosocial adversity. For this analysis, genotypes were classified according to the presence of the minor C allele, and psychosocial adversity was determined using a tripartite split in the psychosocial adversity ratings (low: $0-1$, moderate: $2-3$, and high: $\geq 4$ adversity factors present).

\section{Associated Alcohol Dependence in Adults With hPer1 SNP rs3027172}

Since we were interested in examining whether Perl has a more general relevance for adult alcohol dependence, we analyzed 2,184 individuals (adult patients with alcohol dependence, $\mathrm{N}=1,006$; comparison subjects, $\mathrm{N}=1,178$ ) of
German descent who were not assessed for psychosocial adversity (see Table 1 in the data supplement). Because it is unlikely that all alcohol-dependent individuals were drinking alcohol in response to a highly adverse psychosocial load, this sample might have reduced power to detect drinking behavior resulting from gene-by-environment 
TABLE 1. Haplotypic Association of Human Period 1 (hPer1) Single Nucleotide Polymorphisms (SNPs) With Frequency of Heavy Drinking in Adolescents $(\mathrm{N}=\mathbf{2 7 3})$

\begin{tabular}{|c|c|c|c|c|c|c|c|c|}
\hline \multirow[b]{2}{*}{ Haplotype ${ }^{a}$} & \multicolumn{3}{|c|}{ SNP and Allele } & \multirow[b]{2}{*}{$\begin{array}{l}\text { Haplotype } \\
\text { Frequency }\end{array}$} & \multicolumn{3}{|c|}{ Analysis $^{b}$} & \multirow[b]{2}{*}{ Beta } \\
\hline & rs2735611 (+) & rs2304911 (+) & rs3027172 (+) & & $\begin{array}{c}\text { Haplotype- } \\
\text { Specific Test }\left(\chi^{2}\right)\end{array}$ & $\mathrm{df}$ & $\mathrm{p}^{\mathrm{c}}$ & \\
\hline $\mathrm{H} 1$ & $\mathrm{~T}$ & $\mathrm{~T}$ & $\mathrm{~T}$ & 0.605 & 3.29 & 1 & 0.07 & -0.273 \\
\hline $\mathrm{H} 2$ & $\mathrm{~T}$ & $\mathrm{~T}$ & $\mathrm{C}$ & 0.267 & 8.75 & 1 & 0.003 & 0.495 \\
\hline $\mathrm{H} 3$ & $\mathrm{C}$ & $\mathrm{T}$ & $\mathrm{T}$ & 0.128 & 1.57 & 1 & 0.21 & -0.291 \\
\hline
\end{tabular}

a Haplotypes with a frequency $>0.05$ were tested.

${ }^{\mathrm{b}}$ An omnibus test showed statically significant association $\left(\chi^{2}=9.259, \mathrm{df}=2, \mathrm{p}<0.02\right)$.

c Corrected empirical $p$ values as determined by 10,000 permutations are shown.

TABLE 2. Regression Model Analyses of the Effects of the rs3027172 Human Period 1 (hPer1) Genotype, Psychosocial Adversity, and Their Interaction on Adolescent Drinking ${ }^{a}$

\begin{tabular}{|c|c|c|c|c|c|c|}
\hline \multirow[b]{2}{*}{ Variable } & \multicolumn{2}{|c|}{ hPer1 rs3027172 Genotype } & \multicolumn{2}{|c|}{ Psychosocial Adversity } & \multicolumn{2}{|c|}{ Gene-By-Environment Interaction } \\
\hline & Beta & $\mathrm{p}$ & Beta & $\mathrm{p}$ & Beta & $\mathrm{p}$ \\
\hline Frequency of current heavy drinking & 0.169 & 0.004 & 0.185 & $<0.001$ & 0.619 & 0.013 \\
\hline $\begin{array}{l}\text { Average amount of alcohol consumed } \\
\text { per drinking day }\end{array}$ & 0.149 & 0.009 & 0.163 & 0.004 & -0.140 & 0.567 \\
\hline
\end{tabular}

a All models are adjusted for sex; standardized regression coefficients are derived from linear regression.

${ }^{\text {b }}$ Data indicate $h P e r 1$ rs3027172 genotype-by-psychosocial adversity.

TABLE 3. Alcohol Dependence Associated With the rs3027172 Genotype in Adult Case Patients and Comparison Subjects ${ }^{\mathrm{a}}$

\begin{tabular}{|c|c|c|c|c|c|c|c|c|}
\hline \multirow[b]{3}{*}{ Participants } & \multicolumn{6}{|c|}{ Allele } & & \\
\hline & \multicolumn{2}{|c|}{$C C(N=104)$} & \multicolumn{2}{|c|}{$\mathrm{CT}(\mathrm{N}=799)$} & \multicolumn{2}{|c|}{$\mathrm{TT}(\mathrm{N}=1,281)$} & \multicolumn{2}{|c|}{ Total $(\mathrm{N}=2,184)$} \\
\hline & $\mathrm{N}$ & $\%$ & $\mathrm{~N}$ & $\%$ & $\mathrm{~N}$ & $\%$ & $\mathrm{~N}$ & $\%$ \\
\hline Case patients & 56 & 5.57 & 381 & 37.87 & 569 & 56.56 & 1,006 & 100 \\
\hline Comparison subjects & 48 & 4.07 & 418 & 35.47 & 712 & 60.44 & 1,178 & 100 \\
\hline
\end{tabular}

a Analysis using the Cochran-Armitage trend test (one-sided) showed statistical significance $\left(\chi^{2}=2.1347, \mathrm{df}=1, \mathrm{p}<0.02\right.$ [odds ratio $=1.161,95 \%$ confidence interval=1.008-1.336]).

interactions, such as the aforementioned one. Nevertheless, we found a significant association of carriers of the $\mathrm{C}$ allele of rs3027172 with alcohol dependence $(\mathrm{p}<0.02$; Cochran-Armitage trend test, uncorrected: odds ratio $=1.161$, 95\% confidence interval=1.008-1.336) (Table 3), indicating the relevance of $h$ Perl rs3027172 in more advanced phases of alcohol abuse and dependence.

\section{Cortisol-Induced, Genotype-Specific Transcriptional Activation of hPer1 Involving Binding of the Snail1 Transcription Factor}

We next investigated molecular mechanisms, which might underlie the observed Perl-dependent stress response. We selected six hPerl B-lymphoblastoid cell lines according to the rs3027172 genotype. First, we analyzed genotype-specific expression of $h P e r l$ in synchronized, unstimulated B-lymphoblastoid cell lines and found a significantly higher expression $(\mathrm{p}<0.05)$ in CC cell lines relative to TT cell lines (Figure 3 ). Since a glucocorticoid-induced expression of Perl was previously reported (12), we investigated the effect of the stress hormone cortisol in a physiologically relevant dose on genotype-specific expression of
hPer 1 mRNA using quantitative real-time PCR in genotypespecific B-lymphoblastoid cell lines. Following incubation with cortisol $(1 \mu \mathrm{M})$ for a duration of 4 hours, we observed a fourfold significant increase $(\mathrm{p}<0.01)$ in $h$ Perl mRNA in cell lines carrying the TT genotype of rs3027172, whereas no cortisol-induced stimulation in hPerl expression could be observed in cells carrying the CC genotype.

To investigate the molecular basis of the observed genotype-specific transcriptional activation, we conducted bioinformatic functional prediction analyses. The rs3027172 SNP is localized in the promoter region of the hPerl gene, where it is flanked by two putative transcription factor binding sites. One site is a binding site for the $\mathrm{c}$-Rel protein, a member of the NF- $\mathrm{KB}$ (nuclear factor kappa-light-chain-enhancer of activated B cells) family of transcription factors (21); the other is similar to an E2-box binding site for members of the Snail family of transcriptional regulators (22) (Figure 4). Presence of the $\mathrm{C}$ allele at rs3027172 destroys all similarity of this DNA sequence with an E2-box.

To experimentally validate the predicted disruption of the E2-box transcription factor binding site by rs3027172, 
FIGURE 3. Expression of the Human Period 1 (hPer1) Gene in TT- and CC-Allele Cell Lines $^{\mathrm{a}}$

A

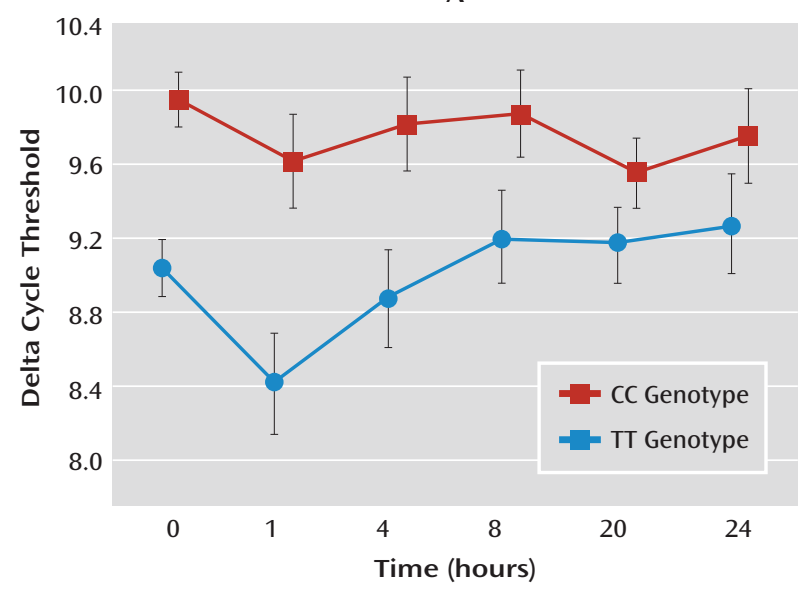

B

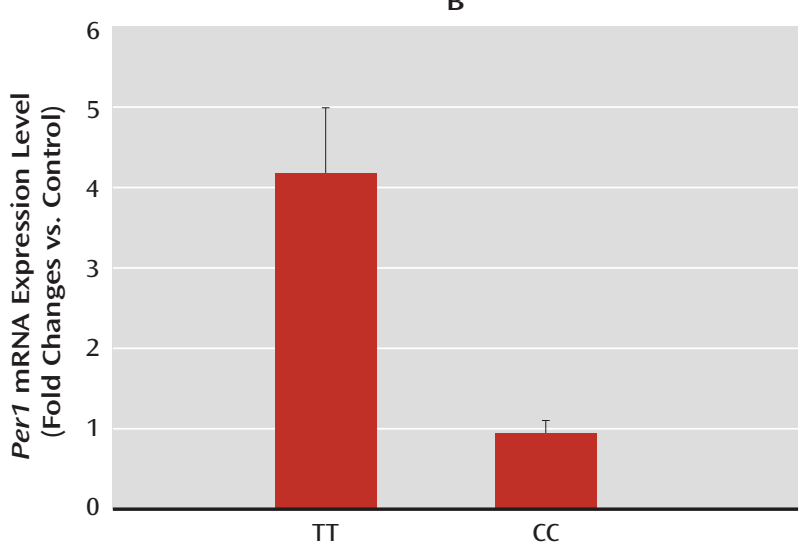

Genotype of the Cell Lines

a The top image (A) depicts genotype-specific expression of the $h P e r 1$ gene in human lymphoblastoid cell lines. Cells were synchronized with a medium containing 50\% horse serum for 2 hours and then replaced with a serum-free medium. Per1 mRNA levels were assessed using quantitative real-time polymerase chain reaction at 0 hours, 1 hour, 4 hours, 8 hours, 20 hours, and 24 hours. Results are shown with delta cycle threshold values normalized to the GAPDH gene. Relative Per1 expression levels were 1.7-fold higher in cell lines carrying the CC allele than in cell lines carrying the TT allele ( $p<0.05$, multimeasure-repeat analysis of variance). Data show the mean (SD) delta cycle threshold values for seven cell lines with the TT allele and six cell lines with the CC allele of the hPer1 SNP rs3027172. The bottom image (B) depicts genotype-specific expression of Per 1 mRNA following stimulation with cortisol $(1 \mu \mathrm{M})$. Treatment with cortisol $(1 \mu \mathrm{M})$ for 4 hours resulted in a 4.09 -fold increase of hPer1 gene expression in cell lines with the TT genotype relative to a 0.92 -fold increase in cell lines with the CC genotype $(p<0.01$ [SE $=0.90])$. Data show the fold changes in Per1 gene expression after cortisol treatment compared with gene expression in the controls, which were incubated with the same concentration of ethanol as the cortisol-treated cells.

we conducted electrophoretic mobility shift assays and investigated whether there is a DNA binding factor that differentially binds to $\mathrm{T}$ and $\mathrm{C}$ alleles of this SNP. Extracts of THP-1 (human acute monocytic leukemia cell line) cells, incubated with labeled c-Rel oligonucleotide, produced a specific c-Rel/NF- $\kappa \mathrm{B}$ complex (Figure 4). To induce c-Rel protein, these cells were activated with lipopolysaccharide. The T- and C-allele hPerl oligonucleotides did not form complexes with c-Rel and NF- $\mathrm{KB}$, as evident from competition experiments with a labeled c-Rel probe and from experiments in which T- and C-allele hPerl oligonucleotides were used as labeled probes. However, incubation of the T-allele $h$ Per 1 probe with the extract produced a novel complex, the formation of which was blocked by unlabeled T-allele hPerl oligonucleotide but not by C-allele

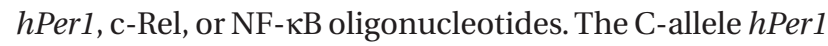
probe also formed this complex but with lower intensity. Thus, this protein factor had higher affinity for binding to T-allele hPerl oligonucleotide compared with C-allele hPer1 oligonucleotide. The T-allele hPerl binding factor demonstrated predominantly nuclear localization in the human brain and was also present at high levels in rat embryonic brain. Oligonucleotide with a canonical E2-box but not a mutated E2-box blocked binding of the factor to the T-allele hPerl probe, suggesting that T-allele $h$ Perl binding factor is an E-box binding protein. Furthermore, monoclonal anti-Snail-antibodies, but not unrelated mouse immunoglobulin $\mathrm{G}$ antibodies, depleted formation of the novel complex, suggesting that T-allele Perl binding factor is identical to the Snaill transcription factor.

\section{Discussion}

Gene-by-environment interactions account for substantial heterogeneity in response to environmental factors contributing to psychiatric disorders (23). Circadian and stress-response systems are important physiologic mediators of environmental influences. In research on alcohol dependence, stress-related gene-by-environment interactions have been described (1), and one prominent example relates to the finding that CRHR1 moderates the effect of psychosocial stress on alcohol consumption in rodent animal models $(20,24)$ as well as in humans (25, 26). In the present article, we show that psychosocial stress moderates the effect of circadian rhythm gene Per 1 on excessive alcohol drinking. Mutant mice that lack a functional Perl gene, as a result of a genetic deletion of the PAS-binding domain, responded to repeated adverse stress exposure with enhanced alcohol consumption. This finding translates to our two human samples (one cohort of adolescents with a high adverse psychosocial load and one adult case-control sample of patients meeting DSMIV criteria for alcohol dependence and comparison subjects, encompassing 2,457 individuals total).

We further examined underlying molecular mechanisms of the observed gene-by-environment interaction and conclude-from a series of in vitro experimentsthat these associations might be caused by cortisol-induced transcriptional activation of Per1, which appears to involve genotype-specific binding of the Snaill transcription factor. Although it has been demonstrated that 
FIGURE 4. Genotype-Specific Transcriptional Factors Binding to the rs3027172 Single Nucleotide Polymorphism (SNP) of the Human Period 1 (hPer1) Gene

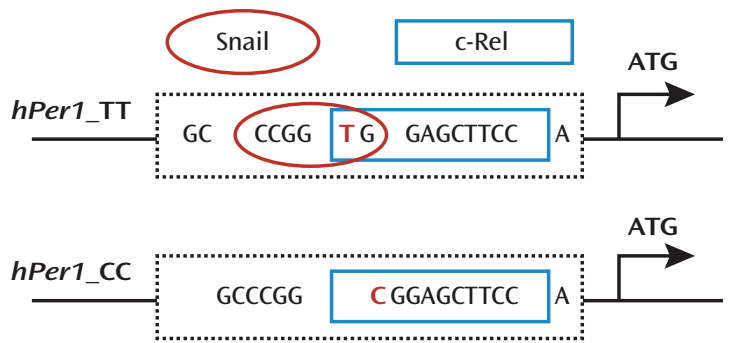

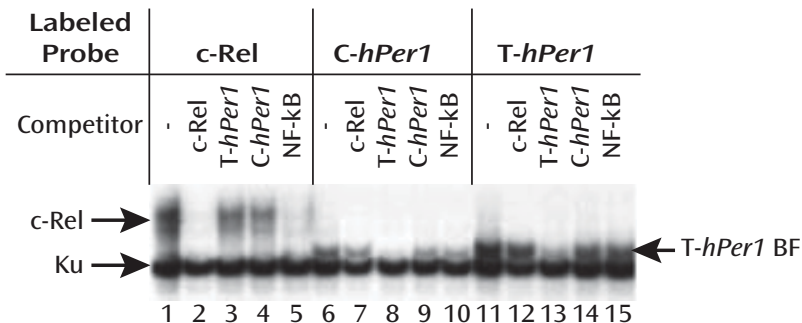

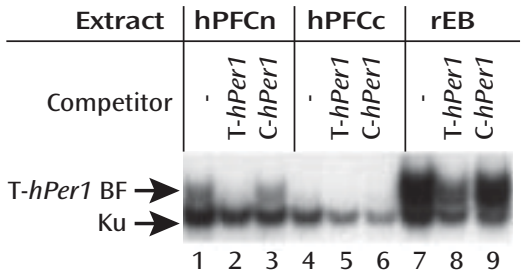

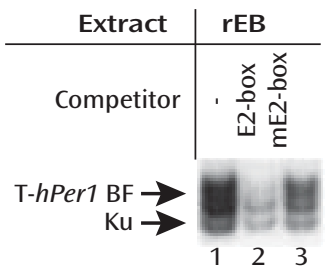

E

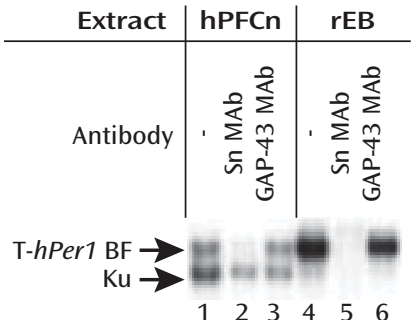

a) A schematic drawing of transcription factors binding to the rs3027172 (SNP2) region in the $h P e r 1$ gene is shown. The localization of SNP2 in $h P e r 1$ is depicted in red. In the TT allele of $h P e r 1$, DNA sequences around SNP2 are identified by the following two transcription factors: Snail and c-Rel. The $\mathrm{C}$ allele $>$ T allele substitution of rs3027172 results in the disappearance of the Snail transcription factor binding site in the $\mathrm{C}$ allele. B) Results from an electrophoretic mobility shift assay are also shown. Extracts of human lipopolysaccharide-activated monocytic THP-1 cells (lane 6), incubated with labeled c-Rel oligonucleotide, produced a specific c-Rel/NF- $\kappa$ B complex (lanes 1, 2, 5). T- and C-allele hPer1 (T-hPer1 and C-hPer1) oligonucleotides did not form complexes with c-Rel and NF- $\kappa$ B, as evident from competition experiments with a labeled c-Rel probe (lanes 3,4) and from experiments in which these oligonucleotides were used as labeled probes (lanes 6-15). A novel complex was produced with the T-hPer1 probe (lanes 11-15) and, with lower intensity, with the C-hPer1 probe (lanes 6-10). T-hPer1 binding factor (BF) showed higher affinity to the T allele (lane 13) relative to the $C$ allele (lane 14) of Per1, as evident from competition experiments. Nonspecific DNA binding complex was formed by Ku protein, which preferentially binds to double-stranded DNA ends and is abundant in human brain tissues. C) Brain expression of T-Per1 BF is shown. T-Per1 BF is present in the adult human brain, where it shows predominantly nuclear localization, as well as in the rat embryonic brain (rEB). Human prefrontal cortex nuclear (hPFCn) extract (lanes 1-3) and human prefrontal cortex cytosolic (hPFCc) fraction (lanes 4-6), prepared from prefrontal cortical tissue obtained from a 56-year-old man, and total extract of rEB tissue (lanes 7-9), obtained from 18-day-old embryos, were analyzed by electrophoretic mobility shift assay. D) Inhibition of T-Per1 BF formation by E-box oligonucleotide is shown. Wild-type E-box (E-box [lane 2]) oligonucleotide but not mutant E-box (mE-box) oligonucleotide (lane 3) inhibited the formation of T-Per1 BF with the T-Per1 probe. E) Inhibition of T-Per1 BF formation by anti-Snail-monoclonal antibodies (Sn-MAb) is shown. The Sn-MAb $(0.5 \mu \mathrm{g}$ [lanes 2, 5]), but not the unrelated anti-GAP45 monoclonal antibodies (1.0 $\mu \mathrm{g}$ [lanes 3, 6]), completely depleted complexes formed by T-hPer1 BF from hPFC (lanes 2, 3) and rEB (lanes 5, 6) with the T-hPer1 probe.

corticotropin-releasing factor is a primary mediator of extrahypothalamic behavioral stress response (27), recent evidence suggests that stress-induced glucocorticoids can modulate the activity of the brain reward pathway and thus may account for individual vulnerability to the reinforcing effects of drugs of abuse $(9,28)$.

The Per1 $1^{\text {Brdml }}$-mutant mice did not differ in home-cage total alcohol consumption (for detailed information, see Zghoul et al. [19]) but did exhibit a different noncircadian drinking pattern relative to their wild-type littermates. However, when exposed to repeated stress, the mutant mice showed more pronounced stress-induced alcohol intake than respective littermate comparison mice. Importantly, this effect was observed in three independent experiments applying different stressors (social defeat stress, swim stress, and foot shock stress). The most pronounced effects were observed with social defeat stress closely mimicking psychosocial stress in humans (20).
Our data further demonstrate that a genetic variationSNP rs3027172-in the promoter region of the hPerl gene is associated with the effect of psychosocial stress on the frequency of heavy drinking in adolescents. In this age group, environmental influences are a more important determinant of alcohol consumption than they are in adulthood (29). Problematic drinking behavior in adolescents with frequent episodes of heavy drinking is associated with coping motives, including coping with psychosocial stress (30).

Frequent heavy drinking in adolescents in an attempt to cope with psychosocial stress is one entry mechanism into compulsive alcohol-dependent behavior (31-33), partly because of neuroplastic processes in the maturing brain, which confer a high vulnerability to drugs as well as alcohol (33). In comparison, the association of the hPer1 SNP rs3027172 with alcohol dependence in adults not only indicates the role of Perl as an entry mechanism into addic- 
tive behavior but also suggests its relevance for manifestation of alcohol dependence. The modest strength of the observed association may reflect the heterogeneity of the alcohol-dependent sample with respect to environmental exposure to adverse stress.

Cortisol is a main mediator of stress responding and serves as a master switch in the control of neuronal and network responses that underlie behavioral adaptations to stress $(2,4)$. There is increasing evidence that Perl is a target gene for glucocorticoids, including cortisol in mice (12) as well as in humans (13). In line with these observations, we found significant cortisol-induced increase in the levels of $h$ Perl transcripts in human B-lymphoblastoid cell lines, which carry the protective genotype, but we did not find increased hPerl expression following cortisol exposure in cells carrying the risk genotype (rs3027172). Therefore, we hypothesize that there might be an altered response to stress-induced cortisol increase in carriers of the rs3027172 risk allele (C allele). Our electrophoretic mobility shift assay data further suggest that this altered stress response might be the result of a decreased binding affinity of the zinc finger protein Snaill $(21,22)$ to the rs3027172 C allele. This transcription factor is expressed in brain regions relevant to stress-induced drinking behavior, such as the prefrontal cortex, nucleus accumbens, and amygdala (www.brain-map.org).

In conclusion, we provide evidence for an involvement of the Perl gene in psychosocial stress-induced alcohol drinking behavior. Based on the observation of increased stress-induced alcohol consumption in $\operatorname{Perl}^{\text {Brdml }}$-mutant mice, we demonstrated a gene-by-environment interaction whereby psychosocial stress moderates the association of risky alcohol drinking in adolescents with the hPerl promoter SNP rs3027172. This finding was further validated in an alcohol-dependent case-control sample. The rs3027172 genotype might be involved in cortisol-induced genotype-specific transcriptional activation of hPerl, which is mediated in part by the transcription factor Snaill. Although the interpretation of gene-by-environment interaction in genetic association studies is complicated by the fact that environmental and genetic components are bi-directionally interconnected (i.e., the environment and the individual affect each other) $(25,26)$, our in vitro and in vivo functional genetic analyses suggest that the effects of exposure to psychosocial stress on risky alcohol consumption are mediated in part by variation in the Perl gene.

\section{Drs. Dong and Bilbao contributed equally to this study.}

Received Nov. 1, 2010; revisions received March 16, April 18, and April 25, 2011; accepted April 29, 2011 (doi: 10.1176/appi. ajp.2011.10111579). From the Medical Research Council Social, Genetic and Developmental Psychiatry Centre, Institute of Psychiatry, King's College London, London; the Central Institute of Mental Health, University of Heidelberg, Mannheim, Germany; the Uppsala Biomedical Centre, Uppsalla, Sweden; the Department of Psychiatry and Psychotherapy, University of Regensburg-Bezirksklinikum, Regensburg, Germany; the Department of Psychiatry and Psychotherapy, Technische Universität Dresden, Dresden, Germany; the
Neuroimaging Center, Department of Psychology, Technische Universität Dresden, Dresden, Germany; the Department of Genomics, Life and Brain Centre, University of Bonn, Bonn, Germany; the Department of Psychiatry and Psychotherapy, University of Munich, Munich; the Department of Medicine, Unit of Biochemistry, University of Fribourg, Fribourg, Switzerland; and the Centre National de Genotypage, Evry, France. Address correspondence to Dr. Schumann (gunter.schumann@kcl.ac.uk).

Dr. Wodarz has received speaker's bureau honoraria from Essex Pharma and Janssen-Cilag. All other authors report no financial relationships with commercial interests.

Supported by the European Commission FP-6 Integrated Project IMAGEN (grant PL037286) (Drs. Schumann, Rietschel, Desrivieres, and Spanagel; the European Commission FP-7 Project ADAMS (Dr. Schumann); the United Kingdom Department of Health National Institute for Health Research-Biomedical Research Centre (Dr. Schumann); and the Medical Research Council Developmental Pathways Into Adolescent Substance Abuse program (grant 93558) (Drs. Schumann and Lourdusamy) as well as grants from AFA Forsäkring; the Research Foundation of the Swedish Alcohol Retail Monopoly; the Swedish Science Research Council; the Swedish National Drug Policy Coordinator (Dr. Bakalkin); Torsten och Ragnar Söderbergs stiftelser (Dr. Balkin); and the German Research Foundation (Drs. Laucht and Smolka) (grants DFG Sm80/2-2, Sm80/5-1, and Sm80/52). Also supported by the German Federal Ministry of Education, through the National Genome Research Network initiative (grant FKZ 01GS08152), and the European Commission (grant FP6, DG RTD project PHECOMP, number, LHSM-CT-2007-037669).

The authors thank Professor I. Virtanen for providing anti-Snail antibodies as well as Drs. I. Bazov, H. Watanabe, and M.M. Taqi for their assistance with the experiments.

\section{References}

1. Spanagel R: Alcoholism: a systems approach from molecular physiology to addictive behavior. Physiol Rev 2009; 89:649-705

2. McEwen BS: Physiology and neurobiology of stress and adaptation: central role of the brain. Physiol Rev 2007; 87:873-904

3. Moore-Ede MC: Physiology of the circadian timing system: predictive versus reactive homeostasis. Am J Physiol 1986; 250:R737-R752

4. de Kloet ER, Joels M, Holsboer F: Stress and the brain: from adaptation to disease. Nat Rev Neurosci 2005; 6:463-475

5. Buijs RM, Scheer FA, Kreier F, Yi C, Bos N, Goncharuk VD, Kalsbeek A: Organization of circadian functions: interaction with the body. Prog Brain Res 2006; 153:341-360

6. Nader N, Chrousos GP, Kino T: Interactions of the circadian clock system and the HPA axis. Trends Endocrinol Metab 2010; 21:277-286

7. Dube SR, Miller JW, Brown DW, Giles WH, Felitti VJ, Dong M, Anda RF: Adverse childhood experiences and the association with ever using alcohol and initiating alcohol use during adolescence. J Adolesc Health 2006; 38:444.e1-444.e10

8. Pilowsky DJ, Keyes KM, Hasin DS: Adverse childhood events and lifetime alcohol dependence. Am J Public Health 2009; 99:258-263

9. Uhart M, Wand GS: Stress, alcohol and drug interaction: an update of human research. Addict Biol 2009; 14:43-64

10. Spanagel R, Rosenwasser AM, Schumann G, Sarkar DK: Alcohol consumption and the body's biological clock. Alcohol Clin Exp Res 2005; 29:1550-1557

11. Bechtold DA, Gibbs JE, Loudon AS: Circadian dysfunction in disease. Trends Pharmacol Sci 2010; 31:191-198

12. Yamamoto $T$, Nakahata $Y$, Tanaka $M$, Yoshida $M$, Soma $H$, Shinohara K, Yasuda A, Mamine T, Takumi T: Acute physical stress elevates mouse period1 mRNA expression in mouse peripheral tissues via a glucocorticoid-responsive element. J Biol Chem 2005; 280:42036-42043

13. Reddy TE, Pauli F, Sprouse RO, Neff NF, Newberry KM, Garabedian MJ, Myers RM: Genomic determination of the gluco- 
corticoid response reveals unexpected mechanisms of gene regulation. Genome Res 2009; 19:2163-2171

14. Takahashi S, Yokota S, Hara R, Kobayashi T, Akiyama M, Moriya T, Shibata S: Physical and inflammatory stressors elevate circadian clock gene mPer1 mRNA levels in the paraventricular nucleus of the mouse. Endocrinology 2001; 142:4910-4917

15. Zheng B, Albrecht U, Kaasik K, Sage M, Lu W, Vaishnav S, Li Q, Sun ZS, Eichele G, Bradley A, Lee CC: Nonredundant roles of the mPer1 and mPer2 genes in the mammalian circadian clock. Cell 2001; 105:683-694

16. Laucht M, Esser G, Baving L, Gerhold M, Hoesch I, Ihle W, Steigleider P, Stock B, Stoehr RM, Weindrich D, Schmidt MH: Behavioral sequelae of perinatal insults and early family adversity at 8 years of age. J Am Acad Child Adolesc Psychiatry 2000; 39:1229-1237

17. Laucht M, Esser G, Schmidt MH: Developmental outcome of infants born with biological and psychosocial risks. J Child Psychol Psychiatry 1997; 38:843-853

18. Rutter M, Quinton D: Psychiatric disorder: ecological factors and concepts of causation, in Ecological Factors in Human Development. Edited by McGurk H. Amsterdam, North-Holland Publishing, 1977, pp 173-187

19. Zghoul T, Abarca C, Sanchis-Segura C, Albrecht U, Schumann G, Spanagel R: Ethanol self-administration and reinstatement of ethanol-seeking behavior in Per1(Brdm1) mutant mice. Psychopharmacology (Berl) 2007; 190:13-19

20. Sillaber I, Rammes G, Zimmermann S, Mahal B, Zieglgänsberger W, Wurst W, Holsboer F, Spanagel R: Enhanced and delayed stress-induced alcohol drinking in mice lacking functional CRH1 receptors. Science 2002; 296:931-933

21. Parry GC, Mackman N: A set of inducible genes expressed by activated human monocytic and endothelial cells contain kappa B-like sites that specifically bind c-Rel/p65 heterodimers. J Biol Chem 1994; 269:20823-20825

22. Peiró S, Escrivà M, Puig I, Barberà MJ, Dave N, Herranz N, Larriba MJ, Takkunen M, Francí C, Muñoz A, Virtanen I, Baulida J, García de Herreros A: Snail1 transcriptional repressor binds to its own promoter and controls its expression. Nucleic Acids Res 2006; 34:2077-2084

23. Caspi A, Moffitt TE: Gene-environment interactions in psychiatry: joining forces with neuroscience. Nat Rev Neurosci 2006; 7:583-590
24. Hansson AC, Cippitelli A, Sommer WH, Fedeli A, Björk K, Soverchia L, Terasmaa A, Massi M, Heilig M, Ciccocioppo R: Variation at the rat Crhr1 locus and sensitivity to relapse into alcohol seeking induced by environmental stress. Proc Natl Acad Sci U S A 2006; 103:15236-15241

25. Treutlein J, Kissling C, Frank J, Wiemann S, Dong L, Depner M, Saam C, Lascorz J, Soyka M, Preuss UW, Rujescu D, Skowronek MH, Rietschel M, Spanagel R, Heinz A, Laucht M, Mann K, Schumann G: Genetic association of the human corticotropin releasing hormone receptor 1 (CRHR1) with binge drinking and alcohol intake patterns in two independent samples. Mol Psychiatry 2006; 11:594-602

26. Blomeyer D, Treutlein J, Esser G, Schmidt MH, Schumann G, Laucht M: Interaction between CRHR1 gene and stressful life events predicts adolescent heavy alcohol use. Biol Psychiatry 2008; 63:146-151

27. Heilig M, Koob GF: A key role for corticotropin-releasing factor in alcohol dependence. Trends Neurosci 2007; 30:399-406

28. Desrivières $S$, Lourdusamy A, Müller C, Ducci F, Wong CP, Kaakinen M, Pouta A, Hartikainen AL, Isohanni M, Charoen P, Peltonen L, Freimer N, Elliott P, Jarvelin MR, Schumann G: Glucocorticoid receptor (NR3C1) gene polymorphisms and onset of alcohol abuse in adolescents. Addict Biol 2011; 16:510-513

29. Rose RJ, Dick DM, Viken RJ, Pulkkinen L, Kaprio J: Drinking or abstaining at age 14 ? a genetic epidemiological study. Alcohol Clin Exp Res 2001; 25:1594-1604

30. Buchmann AF, Schmid B, Blomeyer D, Zimmermann US, Jennen-Steinmetz C, Schmidt MH, Esser G, Banaschewski T, Mann K, Laucht M: Drinking against unpleasant emotions: possible outcome of early onset of alcohol use? Alcohol Clin Exp Res 2010; 34:1052-1057

31. Viner RM, Taylor B: Adult outcomes of binge drinking in adolescence: findings from a UK national birth cohort. J Epidemiol Community Health 2007; 61:902-907

32. Vengeliene V, Celerier E, Chaskiel L, Penzo F, Spanagel R: Compulsive alcohol drinking in rodents. Addict Biol 2009; 14:384396

33. Chambers RA, Taylor JR, Potenza MN: Developmental neurocircuitry of motivation in adolescence: a critical period of addiction vulnerability. Am J Psychiatry 2003; 160:1041-1052 